\title{
METÁFORAS DO FUTEBOL NO PORTUGUÊS BRASILEIRO: UMA ABORDAGEM COGNITIVA
}

\author{
José Genival Bezerra Ferreira \\ Universidade de Santiago de Chile \\ jose.ferreira@usach.cl
}

Recibido: 27/05/2018 - 11/10/2018
doi.org/10.17533/udea.lyl.n75a04

\begin{abstract}
Resumo: O trabalho constitui uma análise qualitativa das expressões metafóricas encontradas no domínio do futebol brasileiro, no âmbito da Copa do Mundo de Futebol, realizada no Brasil, em 2014. O corpus foi formado por manchetes coletadas em websites que trataram do tema. Tomando como fundamentação teórica pressupostos da Linguística Cognitiva, com destaque para a Teoria da Metáfora Conceptual, o estudo mostrou como as construções de metáforas, no português brasileiro, ligadas ao futebol, vão desencadear diferentes domínios, como: «futebol é guerra», «futebol é política»; levando-nos a refletir, dessa forma, a importância desse esporte para a construção da identidade nacional.
\end{abstract}

Palavras-Chave: Linguística Cognitiva; Metáfora Conceptual; Futebol.

\section{SOCCER METAPHORS IN BRAZILIAN PORTUGUESE: A COGNITIVE PERSPECTIVE}

\begin{abstract}
The work is composed by a qualitative analysis of metaphoric expressions in Brazilian soccer with reference to the Soccer World Cup, which took place in Brazil, in 2014. The essence of this theme was addressed in articles collected from websites. Based on the foundation of presumption theory of Cognitive Linguistics with emphasis in the theory of Conceptual Metaphor, the study showed that the construction of metaphors, in Brazilian Portuguese, connected to soccer, will develop different expressions, such as: «soccer is war», «soccer is politics», and therefore making them reflect in the importance of this sport in building the identity of the Brazilian people.
\end{abstract}

Keywords: Cognitive Linguistics; Conceptual Metaphor; Soccer. 


\section{Introdução}

ob o prisma da Linguística Cognitiva, mais especificamente da Teoria da Metáfora $\checkmark$ Conceptual, o presente trabalho investiga os mecanismos cognitivos no discurso publicitário futebolístico no português brasileiro. Analisamos, assim, os mecanismos cognitivos, com especial atenção às metáforas conceituais, contidas em manchetes de textos publicitários futebolísticos que trataram a respeito da Copa do Mundo de Futebol realizada no Brasil em 2014. No que tange às metáforas, é válido destacar, não a estudamos como elas têm sido tradicionalmente compreendidas, no sentido comum, como elemento de arte retórica, mas como algo mais abrangente que opera em todos os níveis da atividade cognitiva.

Partimos da hipótese de que as expressões metafóricas futebolísticas em manchetes funcionam como estratégias para persuadir o público-leitor e que se a metáfora não está apenas na linguagem, mas no pensamento, esse pensamento é compartilhado pelos indivíduos de um determinado grupo social, é possível que as construções metafóricas referentes ao futebol sejam apenas uma extensão das metáforas convencionais do cotidiano.

Optamos pelo texto jornalístico futebolístico, mais especificamente a notícia, como objeto de análise por constituir uma forma de comunicação essencial na veiculação de sentidos, dos quais os valores simbólicos influenciam cultural e socialmente, pois a associamos a situações sociocomunicativas que circundam no nosso dia a dia. Todas têm uma função em comum, isto é, uma intencionalidade almejada pelo discurso que as constitui. Esses efeitos se divergem, a depender do objetivo requerido por meio do ato comunicativo.

A motivação em realizar este estudo justifica-se pelo interesse em compreender a publicidade escrita do futebol no português brasileiro que está numa crescente pertinência em decorrência dos eventos da Copa do Mundo de Futebol (realizada em 2014) e dos Jogos Olímpicos (realizados em 2016) no Brasil. Isso nos possibilita formar um espaço propício de reflexão linguística. Ademais, justificamos a escolha do tema na medida em que consideramos a importância do papel do futebol na sociedade brasileira. Por ser um esporte popular de massa, que atinge todas as classes, forma um símbolo da identidade nacional que ocupa lugar de destaque na visão e conceptualização do país (Bellos, 2003).

A investigação que ora se apresenta está dividida nos seguintes pontos: o primeiro introduz a escolha do tema a desenvolver, bem como os objetivos que direcionam o trabalho e o levantamento das hipóteses. No ponto 2, explicitamos o enquadramento teórico em que o estudo se apoia, frente a uma breve apresentação da Linguística Cognitiva e, em relevo, da Teoria da Metáfora Conceptual. No ponto 3, abordamos o 
discurso jornalístico futebolístico. No ponto 4 , destacamos a questão da metodologia utilizada. O ponto 5 apresenta a análise das manchetes seguido das conclusões. E, por último, as referências consultadas e os anexos.

\section{Linguística Cognitiva como ciência cognitiva}

A Linguística Cognitiva adquire um papel importante no âmbito da Linguística, sendo de referir os trabalhos de Augusto Soares da Silva (2001), José Pinto de Lima (1989), Hanna Batoréo (2004), Maria Clotilde de Almeida (1995) e José Teixeira (2001). De maneira geral podemos afirmar que a Linguística Cognitiva tem seu início nos estudos críticos aos paradigmas estruturalista e generativa, que viam a linguagem como algo autônomo e descreviam a realidade em termos de categorias discretas.

Assim, a Linguística Cognitiva é uma abordagem da linguagem perspectivada como meio de conhecimento e em conexão com a experiência humana do mundo (Cuenca e Hilferty, 2013). As unidades e as estruturas da linguagem são estudadas, não como se fossem entidades autônomas, mas como manifestações de capacidades cognitivas gerais, da organização conceitual, de princípios de categorização, de mecanismos de processamento e da experiência cultural, social e individual (Evans e Green, 2006).

Para Augusto da Silva (2001), a Linguística Cognitiva tem como interesse os seguintes temas: características estruturais da categorização linguística (tais como prototipicidade, polissemia, modelos cognitivos, metáfora e imagens mentais), os princípios funcionais da organização linguística (iconicidade e naturalidade), a interface conceptual entre sintaxe e semântica, a base pragmática — ligada à experiência da linguagem-no-uso - e a relação entre linguagem e pensamento, incluindo questões sobre o relativismo e sobre os universais conceituais.

A Linguística Cognitiva, segundo Cuenca e Hilferty (2013) desenvolve-se a partir de três importantes questões básicas: (i) a linguagem não é um módulo estanque, separado de outras faculdades cognitivas; (ii) a estrutura gramatical de uma língua reflete diferentes processos de conceitualizacão; (iii) o conhecimento linguístico emerge e se estrutura a partir do uso da linguagem. A primeira questão, ao contrário do paradigma de Chomsky, defende a ideia de que a linguagem não constitui um módulo inato e separado de outras capacidades cognitivas do ser humano. A segunda traduz o slogan descrito por Langacker (1988) que explana: «gramática é conceitualização». Conforme o teórico, a gramática de uma língua é o reflexo de distintos processos de conceitualização, ou seja, até mesmo os padrões de combinações das variadas estruturas de uma determinada língua são consequências de processos que ocorrem 
no nível do sistema conceitual humano. A terceira questão da Linguística Cognitiva, desenvolvida por Langacker (1988), é a de que o conhecimento linguístico emerge e se estrutura a partir do uso efetivo da língua em eventos comunicativos reais.

Dessa forma, a linguagem é definida como um domínio cognitivo que se comunica com outros domínios, passando a ser analisada num aspecto mais amplo das Ciências Cognitivas, como a Psicologia, a Antropologia ou as Neurociências, possibilitando, desta maneira, uma pesquisa interdisciplinar, tendo como objetivo final contribuir para a aplicação da investigação e conhecimento da cognição humana. Nesse seguimento, entendemos que a linguagem não se limita a uma simples faculdade comunicativa, ela é, antes de qualquer coisa, uma maneira de conceitualizar a realidade e de refletir essa conceptualização que está presente em todos os âmbitos que circundam a vida de todos nós.

\subsection{Teoria da Metáfora Conceptual}

Podemos mencionar que, no seguimento dos estudos pioneiros na área de Lakoffe Johnson (1980), aparecem outros estudos de Lakoff e Turner (1989) e Raymond Gibbs (1994). Na obra The Poetics of Mind, apresenta-nos a estrutura da cognição humana como um mosaico estruturado por muitos processos poéticos e que a metáfora, em especial, é uma das estruturas fundamentais na conceptualização das experiências que surgem da nossa interação com o mundo que está ao nosso redor. Dito de outra forma, o ser humano acode a metáforas visto que o seu sistema conceptual é em boa parte constituído de maneira metafórica (Lakoffe Johnson, 1980, 2002; Gibbs ,1994).

Os primeiros trabalhos em metáfora conceptual focavam especificamente em verificar a sistematicidade dos conceitos metafóricos e analisá-los sob diferentes pontos de vista (Gibbs, 2008; Soriano, 2012). Na atualidade, notamos um crescente interesse em questionar os fatores contextuais que explicam o surgimento de metáforas na interação cotidiana (Kövecses, 2015), bem como na análise da metáfora conceptual em discursos especializados (Soares da Silva, 2016; Semino e Demjen, 2017; Semino et al., 2018).

A pesquisa que ora se apresenta segue este delineamento, porque se ocupa de uma perspectiva sócio-cognitiva (Romano e Porto, 2016) ao procurar analisar as representações socio-cognitivas são estruturas divididas, social e discursivamente construídas na comunicação, que estabelecem identidades e relações sociais ao serem comunicadas e que estão sujeitas a una transformação continua através do fluxo e refluxo das relações intergrupais. Em conformidade com esse ponto de vista, analisamos as conceptualizações metafóricas sobre o futebol no português brasileiro durante a Copa do Mundo de 2014. 
Dentro dessa linha teórica cognitiva, Lakoff e Johnson (2002) postularam que o nosso pensamento é metafórico, sendo que a metáfora é um instrumento conceitual e não meramente linguístico usado com frequência no cotidiano por todos os indivíduos. Dessa forma, ela não forma apenas um simples recurso estilístico, utilizado para ornamentar textos de caráter literário.

O conceito de metáfora foi redirecionado a partir dos estudos de (Lakoff e Johnson, 2002). Esses autores afirmam que os seres humanos vivem segundo as metáforas que há na cultura em que estão inseridos. Isso nos leva a concluir que as metáforas estão presentes em todos os tipos de linguagem e de discurso, até mesmo na linguagem científica e técnica.

Em Metaphors We Live By, Lakoff e Johnson dividem as metáforas em três tipos: estruturais, orientacionais e ontológicas: As metáforas estruturais ocorrem em situações em que um conceito é metaforicamente estruturado em termos de outro. $\mathrm{Na}$ visão dos teóricos em questão, podemos, por exemplo, estruturar o conceito TEMPO em termos do conceito DINHEIRO, criando a metáfora conceitual TEMPO É DINHEIRO. Essa metáfora, por sua vez, geraria expressões metafóricas, como: "Você está gastando seu tempo" (2002, p. 7). As metáforas orientacionais partem da orientação corporal (acima/abaixo, dentro/fora, frente/trás etc.). Por meio das metáforas orientacionais, projetamos orientações espaciais em objetos, conceitos que não têm uma orientação espacial intrínseca. Quando utilizamos expressões metafóricas, como: «A bola está em frente da pedra» (2002, p. 42), estamos projetando orientações espaciais (no exemplo, "frente") em objetos que não têm uma frente intrínseca. Já as metáforas ontológicas nos permitem ver eventos, ações, estados, ideias e emoções. Por meio das metáforas ontológicas, eventos e ações são conceitualizados metaforicamente como objetos; atividades como substâncias e estados como recipientes. De modo que a metáfora conceitual INFLAÇÃO É UMA ENTIDADE gera expressões metafóricas como "Nós precisamos combater a inflação" (2002, p. 26).

Assim, tem sido amplamente destacado por vários autores, com especial enfoque para Lakoff e Johnson (2002), que a metáfora é uma ferramenta conceptual, funcionando por meio da criação de mapeamentos parciais entre dois domínios cognitivos, o domínio-fonte e o domínio-alvo, de modo que os domínios cognitivos são vistos como campos coerentes do conhecimento que se ajustam ao contexto de determinados conceitos. Nessa perspectiva de pensamento, os mencionados autores pretendem que conceitos abstratos, que se configuram essenciais à existência humana, como por exemplo, o amor, a vida e a morte, são compreendidos e conceitualizados enquanto domínios-alvo, por intervenção de mapeamentos parciais baseados em domínios-fonte concretos, o que leva ao surgimento de metáforas conceptuais, como menciona Lakoff e Johnson (2002, p. 47): “O amor é uma viagem”. É uma amostra 
de metáfora conceptual (não expressão metafórica), que realiza a projeção entre um Domínio de Origem (VIAGEM) e que pode ter várias efetivações linguísticas, como "Estamos numa encruzilhada", "Olha onde chegou a nossa relação" ou "Estamos a ir muito depressa”. São, assim, há diversas expressões linguísticas que transmitem uma única metáfora conceptual. Nessa linha, é conveniente que façamos a diferença entre "metáfora conceptual" e "expressão metafórica". A expressão metafórica equivale a uma expressão linguística que transporta uma metáfora conceptual, ou seja, diz respeito a uma expressão de um pensamento metafórico. Assim sendo, entendemos que uma expressão linguística, veicula imagens mentais que nos dar a possiblidade de projetar diversos domínios, que, linguisticamente, podem se concretizar de muitas formas.

\section{A notícia como discurso futebolístico}

A cultura nacional de qualquer povo constitui um dos principais recursos de identidade cultural. Uma cultura nacional é um discurso, uma forma de construir sentidos que influencia e organiza tanto nossas ações quanto a concepção que temos de nós mesmos. Levando em consideração que o jornalismo futebolístico é também uma prática discursiva, Traquina (2005) observa que ao longo da história, os jornalistas desenvolveram uma maneira própria de falar, ou seja, criaram uma linguagem própria, em que uma das características principais da fala ou da escrita, é a sua qualidade compreensível.

O futebol é um ritual. Tais rituais são tipos naturais de atividades para indivíduos ou membros de uma cultura. Os referidos estudiosos propõem que as metáforas culturais são divulgadas por meio dos rituais e como resultado não há cultura sem ritual. A nosso ver, o futebol é mais propriamente uma expressão cultural e as metáforas encontradas nas manchetes do futebol brasileiro mostram isso, retratando a forma específica como nossa sociedade conceitualiza o futebol (Lakoff e Johnson, 2002). Nessa perspectiva, as metáforas têm o seu lugar cativo na linguagem jornalística do futebol, porque desempenham uma função essencial, principalmente, na transformação de temas de caráter científico e sua terminologia em uma linguagem simples e acessível para todos os grupos sociais.

Quando se refere ao gênero jornalístico denominado notícia, Chaparro (1998) assinala duas maneiras de concebê-lo: (i) em sentido geral, ou seja, o que diz respeito a tudo que a imprensa jornalística pública notadamente o que se publica frequentemente acerca do que se concebe como informação atual e de interesse da população. Dessa maneira, ao se falar em notícia, generalizam-se todos os gêneros discursivos que circulam no jornalismo; (ii) de forma contrária, no sentido mais restrito ou técnico, trata-se de um gênero textual independente dentro dos vários tipos 
de gênero jornalístico cuja função é informar. Nesse segundo modo de ver, a notícia é o tipo de discurso mais banal nos meios de comunicação, pois se presta só a informar o leitor e se apresenta como um texto neutro, sem manifestar opiniões do autor, uma vez que não se faz um estudo profundo do fato noticiado, comprometendo-se em somente mostrar determinado acontecimento. Nessa perspectiva, a notícia não é um fato, porém um relato, no entanto, com uma leitura mais profunda, «iremos perceber a ideologia que reflete e refrata a realidade por ela veiculada e que procura se ocultar sob um texto coberto de consensos e de supostas verdades» (Melo 1992, p. 3).

Autores como Correia (2011), Rodrigues (2007) e Lage (2006a) têm se dedicado em estudar a notícia na tentativa de desvendar as intenções implícitas ante o discurso referencial e informativo aparentemente neutro. Segundo os autores mencionados, essa não é uma tarefa fácil, porque é necessário analisar todo o aparato que circunda o fato noticioso, desde o conteúdo, as condições de produção, o contexto situacional, as unidades paratextuais e supratextuais a fim de compreender a pretensa verdade atravessada pela ideologia.

Sob o prisma cognitivo, van Dijk (1988) aponta a análise da estrutura da notícia para além do nível sentencial. Conforme o autor, a notícia tem uma estrutura de destaque que assinala ao sujeito-leitor que informação é mais relevante dentro da própria notícia. Ademais, indica que «as formas estruturais e os sentidos globais não são arbitrários, mas o resultado de hábitos sociais e profissionais do jornalista» (1988, p. 32). O autor critica a análise da estrutura noticiosa que não se compara aos «contextos cognitivos e socioculturais da produção e recepção de notícias» (1988, p. 34), ao passo que sugere que a análise dessa estrutura da notícia não deixa de considerar as condições sociais, institucionais e profissionais.

\section{Metodologia}

A criação do corpus fez um percurso relativamente linear e envolveu algumas etapas. A primeira foi a recolha do material linguístico para ser analisado, de forma a conseguir as manchetes publicitárias que tragam instrumentos de análise textual, isto é, manchetes que noticiaram sobre a Copa Mundial de Futebol, realizada no Brasil, em 2014.

As referidas manchetes foram selecionadas em três websites: www.folha.uol.com, www.veja.abril.com.br e www.globoesporte.globo.com. A escolha de tais sites se deu pelo fato de serem de empresas jornalísticas conceituadas no país e que atingem o público de todos os níveis sociais. O primeiro trata-se da versão eletrônica do jornal mais lido no Brasil e o segundo, de modo igual, da revista mais lida no país, a Veja. Ambos periódicos abordam assuntos diversos com seção especial dedicada 
ao futebol. E o terceiro website é a versão eletrônica do programa televisivo "Globo Esporte" (aborda apenas questões esportivas) da Rede Globo de Televisão, a de mais audiência em todo o território nacional.

Em um segundo momento, como cada manchete constituiu uma unidade de análise, fizemos fichas para cada unidade que analisamos. A ficha abrange: (i) a própria manchete, (ii) a frase descritiva que localiza a informação, ou seja, traremos uma breve descrição da manchete e (iii) o link que contextualiza a manchete. Delimitamo-nos a coleta do material linguístico a partir do mês de novembro de 2012 ao final de fevereiro de 2013. O mencionado período foi marcado por atritos entre comissão organizadora do evento da FIFA e o Brasil. O motivo girou em torno das especulações se o país (Brasil) teria condições ou não de deixar os 12 estádios prontos para realização do evento.

E, por último, procuramos verificar quais mecanismos cognitivos apresentam os corpora. Ou seja, a análise das manchetes seguirá os princípios da Linguística Cognitiva que introduz uma nova Teoria da Metáfora Conceptual, descrevendo-a como um fenômeno cognitivo que visa a conceitualizar um domínio mental, para isso tomamos como referencial teórico as ideias dos autores mencionados anteriormente.

\section{A análise}

\subsection{Futebol é guerra}

"Arena Pernambuco: o teste de fogo do Brasil dentro da Fifa", in veja.abril. com.br, 06/11/2012.

Futebol é guerra origina a realizações metafóricas cujo domínio-fonte incide sobre adversários, táticas e meios técnicos próprios dos cenários de guerra.

Corpo da notícia: A matéria põe em questionamento se o estádio (arena) ficará pronto para a realização dos jogos ou não, devido às grandes reformas em sua estrutura física, para participar da Copa das Confederações em 2013, considerada o ensaio para a Copa do Mundo de 2014. A FIFA (em francês, Fédération Internationale de Football), vendo o real risco de o referido estádio não ter as obras terminadas, mudaria as estratégias de realização desse evento. O Estádio está localizado na cidade de Recife, capital do estado de Pernambuco, no nordeste brasileiro.

Análise: No título, encontramos metáforas nas expressões "arena" e "teste de fogo". A arena era o local onde os gladiadores se enfrentavam e os toureiros e touros tentavam se espetar. Ou seja, um local de enfrentamentos como no campo de futebol. Em linguagem bélica, o "teste de fogo" significa colocar os soldados sob 
o questionamento se eles são capazes ou não de combater os inimigos. Nesse caso, o cumprimento dos prazos e a entrega da Arena pronta seriam o teste de fogo para o Governo e os envolvidos na reforma. O futebol é em si mesmo, no campo, uma metáfora da guerra, e os próprios jogadores são caracterizados metaforicamente (defesas e atacantes), bem como há chutes que são bombas e mísseis.

\subsection{Futebol é política}

"Copa e eleição vão manter aquecida a criação de emprego", in www1.folha. uol.com.br, 04/01/2013.

Futebol é política origina representações metafóricas que têm como domínio fonte a política.

Corpo da notícia: A notícia apresenta previsões sobre a questão do crescimento econômico do Brasil em decorrência dos eventos que aconteceram no último ano: a Copa Mundial de Futebol e as eleições para presidente da república e governadores dos estados. A Copa de Futebol e as eleições serão responsáveis pela criação de 1,3 milhão de empregos, ou seja, um crescimento de $4 \%$ no PIB. Já para os poucos otimistas, o crescimento não passará de $3 \%$.

Análise: No título da matéria, a copa de futebol foi colocada no mesmo patamar que a eleição presidencial de 2012: ambas proporcionaram crescimento ao mercado por meio da venda de produtos e geração de emprego. "Eleição" vem do latim electionis, "escolha", "permitir a escolha". Derivado do latim eligo = arrancar colhendo, levar, tirar, separar. Assim, eleição é o processo mediante o qual um grupo social escolhe seu governante ou seu representante político por meio do voto. Por meio de um evento, como a Copa de Futebol, a política partidária, através de seus representantes, utilizam metáforas do futebol para explicar desde a rotina administrativa do governo à política externa. Alguns políticos se apropriam da popularidade do futebol e de sua linguagem popular, muitas vezes, para tirarem proveito e se autopromoverem.

\subsection{Futebol é teatro}

"500 dias para a Copa: Rio corre para entregar o Maracanã, palco da final”, in globoesporte.globo.com, 28/01/2013.

Futebol é teatro serve de base a uma imagem metafórica que tem como domíniofonte o teatro.

Corpo da notícia: Faltando apenas 500 dias para a Copa, na época, a matéria abordou se o estádio do Maracanã, que passava por grandes reformas, teria suas obras concluídas ou não dentro do prazo previsto. Considerado o estádio principal 
do evento, localizado no Rio de Janeiro, cidade que segundo as previsões, receberia o maior número de turistas. Dentre as doze outras que realizaram jogos, sediou a partida final, bem como a cerimônia final do evento.

Análise: O seguimento linguístico "palco final”, refere-se ao estádio Maracanã que realizou a partida final da Copa e, consequentemente, a partir desse jogo, conhecemos a seleção campeã. "Teatro", vocábulo grego Théatron ( $\theta \varepsilon ́ \alpha \tau \rho o v)$, estabelece o lugar físico do espectador, "lugar onde se vai para ver" e onde, simultaneamente, acontece o drama como seu complemento visto, real e imaginário. No palco, atores imbuídos de personagens apresentam uma determinada história que desperta na plateia sentimentos variados. No campo, jogadores assumem esse papel. Em suma, seja no estádio de futebol ou no teatro, sentimentos e reações diferentes são despertados. Torcedores de futebol ou espectadores de uma peça teatral se emocionam, riem ou choram dependendo do desenrolar da cena, onde o campo é palco e o palco é campo.

\subsection{Futebol é uma criança}

“Castelão chama a atenção por beleza, mas ainda engatinha nos serviços”, in globoesporte.globo.com, 28/01/2013.

Futebol é uma criança é realizada numa imagem metafórica que apresenta como domínio-fonte bebê.

Corpo da notícia: A notícia pôs em questionamento se o Castelão, estádio localizado na cidade de Fortaleza, nordeste do Brasil, que após sua reforma terminada, estaria ou não em condições de receber os jogos, pois apresentou falhas na infraestrutura. Embora tenha apresentado o projeto arquitetônico mais arrojado, as obras apresentaram defeitos básicos, típicos de incipiente.

Análise: Como um bebê que está aprendendo a dar seus primeiros movimentos, mexendo-se lentamente nas mãos e joelhos ou arrastando o corpo pelo chão, ou seja, engatinhando, assim é o Castelão. O estádio pecou em serviços básicos como acessibilidade, comida e banheiros. Como se os profissionais ali envolvidos estivessem aprendendo, apenas iniciando a arte de construir locais públicos com as devidas conveniências. O projeto de reforma do referido estádio chamou atenção por sua beleza, mas que depois de pronto apresentou essas falhas arquitetônicas.

\subsection{Futebol é desconhecimento}

“A 500 dias da Copa, o Maracanã é um segredo", in veja.abril.com.br, 28/01/2013.

Futebol é desconhecimento é realizada numa imagem metafórica que apresenta como domínio-fonte segredo. 
Corpo da notícia: Mais uma vez, o andamento das obras do estádio do Maracanã é questionado. $\mathrm{O}$ cronograma da etapa final foi mantido em sigilo. O governo do estado prometeu a entrega para o mês de abril. Especulou-se, no entanto, que obras no entorno do estádio não ficariam prontas até a Copa.

Análise: O título indica-nos que o desenrolar das obras do estádio Maracanã são mantidas em segredo, isto é, de desconhecimento do público geral e da imprensa. Manter às escuras tais fatos levaram as pessoas a deduzir que o fato de o governo esconder é um indício que as obras não estavam avançando e se correria o risco real de as obras não ficarem prontas.

\subsection{Futebol é desconhecimento}

"Fifa confirma tecnologia da linha do gol na Copa do Mundo", in esporte.uol. com.br, 19/02/2013.

Futebol é desconhecimento dá corpo a imagens metafóricas que têm com domínio fonte tecnologias sofisticadas para a realização da Copa.

Corpo da notícia: A notícia dá a saber que a Federação Internacional das Associações de Futebol confirmou que a tecnologia da linha do gol seria utilizada na Copa do Mundo e na Copa das Confederações no Brasil em 2014, bem como convidou mais fornecedores a apresentarem propostas.

Análise: A construção da imagem metafórica gira em torno da aplicação de elementos tecnológicos nos jogos da Copa de 2014. A tecnologia de linha de gol seria um recurso tecnológico utilizado para tirar as dúvidas de todos os lances polêmicos. Os lances seriam exibidos em telões nos estádios, para que não houvesse dúvidas aos torcedores. Sob a égide do lema de realizar a melhor Copa do Mundo de Futebol de todos os tempos, os responsáveis pelo evento acreditavam que a tecnologia seria uma aliada indispensável para atingir esse objetivo.

\subsection{Futebol é uma viagem}

"Fifa anuncia passaporte biológico para Copa de 2014", in esporte.uol.com.br, 15/02/2013.

Futebol é uma viagem é realizada numa imagem metafórica que apresenta como domínio-fonte viagem.

Corpo da notícia: A FIFA anuncia que todos os jogadores que disputariam a Copa do Mundo do Brasil-2014 seriam submetidos a um programa de passaporte biológico e começaria a ser implantado em 2013, com o objetivo de reforçar a luta antidoping. 
Análise: Como sabemos, o passaporte é um documento de identidade emitido por um governo nacional que atesta formalmente o portador como nacional de um Estado em particular, e, requisita permissão em nome do soberano ou do governo emissor para o detentor poder cruzar a fronteira de um país estrangeiro. Sem ele, não se viaja. O Passaporte Biológico, citado na notícia, é uma estratégia inovadora no âmbito da luta contra a dopagem no esporte. Ele (o passaporte biológico) seria, na Copa do Mundo, o documento que aprovaria ou não à viagem do jogador para a competição.

\subsection{Futebol é comércio}

"Fifa, Globo e parceiros vão vender 1.500 produtos com a marca da Copa-2014 no Brasil", in esporte.uol.com.br, 09/02/2013.

Futebol é comércio dá corpo a imagens metafóricas que têm como domínio fonte a comercialização de produtos durante a Copa.

Corpo da notícia: As empresas das Organizações Globo que detém o direito exclusivo de explorar em produtos diversos as marcas da Copa do Mundo de 2014 no Brasil, iria colocar no varejo brasileiro 1.500 produtos com o selo de artigo oficial do evento. Trinta e quatro empresas firmariam parceria com a empresa para fabricar os produtos.

Análise: Notamos que o mercado de vendas de produtos, durante a Copa, seria a oportunidade de grandes empresas lucrarem muito. A intenção da empresa "Globo Marca", que abrange uma rede de negócio que vai desde a telecomunicação até alegorias de torcedores, seria fazer do evento um grande centro de compras e, consequentemente, alcançar os pretendidos lucros.

\subsection{Futebol é dança}

"Curtinha: Ronaldo nega samba no pé, mas quer carnaval na final da Copa", in globoesporte.globo.com,11/02/2013.

Futebol é dança é realizada numa imagem metafórica que apresenta como domínio-fonte dança.

Corpo da notícia: Durante o desfile das escolas de samba do Rio de Janeiro, o famoso ex-jogador de futebol, Ronaldo, disse que sonharia com o Brasil campeão e com grande festa em 2014 ao ritmo do samba.

Análise: A imagem metafórica "samba no pé" para representar que o indivíduo sabe dançar esse ritmo musical tem por base uma metonímia. Como sabemos, o 
ritmo samba é considerado marca de identidade do Brasil. Muitas pessoas chegam a afirmar que a tríade samba-carnaval-futebol é a marca maior da identidade brasileira. Na manchete, os três elementos estão presentes na reportarem e apresenta a imagem de que se os jogadores do Brasil (seleção de futebol) tivessem tido o gingado do samba no pé, a mencionada seleção seria campeã.

No bojo do atual trabalho foi possível comprovar a importância das metáforas conceptuais e respectivas realizações metafóricas na esfera da imprensa brasileira, no gênero notícia, no contexto do Mundial realizado no Brasil. Ainda se chegou à conclusão de que, de acordo com a aplicação do enquadramento teórico, podemos comprovar que o postulado precípuo da semântica cognitiva de que o significado é indissociável da experiência física, social e cultural, pelo que experiências diferentes dão origem a metáforas conceptuais e imagens metafóricas diferentes, desvelando, assim, conceitos que direcionam para um dos símbolos da identidade nacional, o futebol, e lugar que ele ocupa na conceptualização do país Brasil.

\section{Conclusões}

Pretendemos no trabalho, mesmo que de forma sucinta, fazer uma análise dos mecanismos cognitivos contidos nas manchetes de futebol que se reportavam sobre a Copa de Futebol realizada no Brasil em 2014. Como cada manchete constituiu uma unidade de estudo, a análise dos mecanismos cognitivos das referidas manchetes sugeriu o seguinte.

*Das nove manchetes de futebol analisadas, quatro delas tratam a respeito da preocupação com a reforma e construção dos estádios; duas se referem às inovações tecnológicas utilizadas nos estádios; duas em relação ao aumento do comércio propiciado pelo evento e uma diz respeito à declaração do ex-jogador de futebol, Ronaldinho.

* As referidas manchetes mostraram que há geralmente semelhanças que podem ser percebidas entre os domínios da experiência que são correlacionadas com as metáforas encontradas no futebol.

*A análise confirma a hipótese de que as manchetes de futebol analisadas giram em torno de tentar convencer o leitor de que o Brasil teria condições de realizar o evento, bem como as construções futebolísticas metafóricas são extensões da linguagem do cotidiano.

Assim, confirmamos que, a partir da análise das referidas manchetes e das teorias acima expostas, a metáfora, ao contrário do que era proposto pela visão tradicional, 
não é apenas um ornamento linguístico, uma figura de linguagem utilizada apenas no discurso poético ou persuasivo, mas, segundo Lakoff e Johnson, está presente no próprio pensamento e na linguagem do dia a dia.

O presente estudo servirá de ponto de partida para um amplo exame dos mecanismos cognitivos nas manchetes de futebol presentes no discurso da mídia no português brasileiro, uma vez que se revelou um campo propício para tal discussão. Esperamos que a pesquisa constitua um apoio aos estudos do discurso desde o ponto de vista mais recente das metáforas conceptuais e que os resultados do trabalho sirvam de instrumento de reavaliação no modo de conceber as notícias como gênero textual.

\section{Referências bibliográficas}

1. Almeida, M. (1995). Transitividade e Trajectória nas Concepções de 'Abrir'e 'Cortar' em Português e Alemão: Análise Prototípico-Analogista. Tese de Doutoramento em Linguística, FLUL, Universidade de Lisboa.

2. Batoréo, H. J. (2004). Linguística Portuguesa: Abordagem Cognitiva. Lisboa: Universidade Aberta.

3. Bellos, A. (2003). Futebol - O Brasil em campo. Rio de Janeiro: Jorge Zahar Editor. 4. Chaparro, M. C. (1998). Sotaques d'aquém e d'além mar: percursos e gêneros do jornalismo português e brasileiro. Santarém: Jortejo.

5. Correia, J. C. (2011). O admirável mundo das notícias: Teorias e métodos. Covilhã: LabCom Books.

6. Cuenca, M. \& Hilferty, J. (2013). Introducción a la Lingüistica Cognitiva. Barcelona: Ariel

7. Deignan, A. (2005). Metaphor and Corpus Linguistics. Amsterdam: John Benjamins.

8. Evans, V. \& Green, M. (2006). Cognitive linguistics: An introduction. Edinburgh: Edinburgh University Press.

9. Gibbs, Raymond. (1994). The Poetics of Mind: Figurative Thought, Language, and Understanding, Cambridge: Cambridge University Press.

10. Gibbs, R. (2008). Metaphor and Thought. The State of the Art. En R. Gibbs (Ed.), The Cambridge Handbook of Metaphor and Thought (pp. 3-13). Cambridge: Cambridge University Press.

11. Kövecses, Z. (2015). Where metaphors come from. Oxford: Oxford University Press.

12. Large, N. (2006b). Linguagem jornalística. São Paulo: Ática.

13. Lakoff, G. \& Johnson, M. (2002). Metáforas da vida cotidiana. Coordenação de tradução: Mara Sophia Zanotto. São Paulo: Mercado das Letras.

14. Lakoff, G. \& Johnson, M. (1980). Metaphors We Live By. Chicago: The University of Chicago Press.

15. Lakoff, G.\& Turner, M. (1989). More Than Cool Reason: A Field Guide to Poetic Metaphor. Chicago: The University of Chicago Press.

16. Langacker, R. W. (1988). A Usage-Based Model in Rudzka-Ostyn. B. Topics in Cognitive Linguistics. Amsterdam/Philadelphia: John Benjamins. 
17. Lima, J. (1989). Significado Avaliativo: para uma Clarificação à Luz de uma Semântica Prática. Dissertação de Doutoramento em Linguística, Faculdade de Letras, Universidade de Lisboa.

18. Melo, J. M. (1992). Gêneros jornalísticos na Folha de S. Paulo. São Paulo: FTD.

19. Rodrigues, N. (2007). À sombra das chuteiras imortais. São Paulo: Cia. das Letras.

20. Romano, M y Porto M.L. (Eds.). (2016). Exploring discourse strategies in social and cognitive interaction. Amsterdam: John Benjamin Publishing Company.

21. Semino, E. y Demjen, Z. (Eds.). (2017). The Routledge Handbook of Metaphor and Language. Londres: Routledge.

22. Semino, E., Demjen, Z., Hardie, A., Payne, S. A. \& Rayson, P. E. (2018). Metaphor, Cancer and the End of Life: A Corpus-based Study Londres: Routledge.

23. Silva, A. S. (1997). «A Linguística Cognitiva. Uma breve introdução a um Novo Paradigma em Linguística», Revista Portuguesa de Humanidades, vol. 1, fasc. 1-2, 59-101.

24. Silva, A. S. (org.). (2001). Linguagem e Cognição: A Perspectiva da Linguística Cognitiva. Braga: Associação Portuguesa de Linguística e Universidade Católica Portuguesa.

25. Soares, A. S. (2016). The persuasive (and manipulative) power of metaphor in 'austerity' discourse. En M. Romano y M. L. Porto (Eds.), Exploring discourse strategies in social and cognitive interaction (pp. 79-108). Amsterdam: John Benjamin Publishing Company.

26. Soriano, C. (2012). La metáfora conceptual. En, I. Ibarretxe-Antuñano y J. Valenzuela, (Eds.), Lingüistica cognitiva (pp. 97-121). Barcelona: Anthropos.

27. Teixeira, J. (2001). A Verbalização do Espaço: Modelos Mentais de Frente/Trás. Dissertação de Doutoramento em Linguística. Centro de Estudos Humanísticos, Universidade do Minho.

28. Traquina, N. (2005). A tribo jornalística uma comunidade interpretativa transnacional. Florianópolis: Insular.

29. van Dijk, T. (1988). News as Discourse. NJ: Erlbaum Associates.

\section{Corpora}

30. “Arena Pernambuco: o teste de fogo do Brasil dentro da Fifa”. http://veja.abril.com.br/noticia/ esporte/arena-pernambuco-o-teste-de-fogo-do-brasil-dentro-da-fifa

31. "Copa e eleição vão manter aquecida a criação de emprego". http://wwwl.folha.uol.com.br/ mercado/1209815-copa-e-eleicao-vao-manter-aquecida-a-criacao-de-emprego.html

31. “500 dias para a Copa: Rio corre para entregar o Maracanã, palco da final”. http://globoesporte. globo.com/futebol/copa-do-mundo/noticia/2013/01/500-dias-para-copa-rio-corre-para-entregaro-maracana-palco-da-final.html

32. "Castelão chama a atenção por beleza, mas ainda engatinha nos serviços". http://globoesporte. globo.com/futebol/copa-do-mundo/noticia/2013/01/castelao-chama-atencao-por-beleza-masainda-engatinha-nos-servicos.html

33. “A 500 dias da Copa, o Maracanã é um segredo". http://veja.abril.com.br/noticia/esporte/a-500dias-da-copa-o-maracana-e-um-segredo

34 "Fifa confirma tecnologia da linha do gol na Copa do Mundo". http://esporte.uol.com.br/ ultimasnoticias/reuters/2013/02/19/fifa-confirma-tecnologia-da-linha-do-gol-na-copa-do-mundo. html 
35. "Fifa anuncia passaporte biológico para Copa de 2014". http://esporte.uol.com.br/ultimas-noticias/ afp/2013/02/15/fifa-anuncia-passaporte-biologico-para-copa-de-2014.html

36. "Fifa, Globo e parceiros vão vender 1.500 produtos com a marca da Copa-2014 no Brasil". http:// copadomundo.uol.com.br/noticias/redacao/2013/02/09/fifa-globo-e-parceiros-vao-vender-1500produtos-com-a-marca-da-copa-2014-no-brasil.html

37. "Curtinha: Ronaldo nega samba no pé, mas quer carnaval na final da Copa". http://globoesporte. globo.com/futebol/copa-do-mundo/noticia/2013/02/curtinha-ronaldo-nega-samba-no-pe-masquer-carnaval-na-final-da-copa.html 